\title{
Effect of Cyclic low temperature conditioning on Stiffness Modulus of Asphalt Concrete based on Non-contact Resonance testing method
}

\author{
Abiy Bekele1 ${ }^{1}$, Nils Ryden ${ }^{2}$,Anders Gudmarsson ${ }^{3}$ and Björn Birgisson ${ }^{4}$ \\ Email:abiy@kth.se,Mobile:+46722845794 \\ ${ }^{1,2}$ Department of Civil and Architectural Engineering, KTH Royal Institute of Technology, \\ Brinellvägen 23, 100 44Stockholm \\ ${ }^{3}$ Peab Asfalt AB,Drivhjulsvägen 11, 12630 Hägersten \\ ${ }^{4}$ Department of Civil Engineering,Texas A\&M University, 3136 TAMU.College Station ,TX 77843- \\ 3136
}

\begin{abstract}
The stiffness modulus behaviors of three different asphalt concrete specimens that are subjected to cyclic cooling and heating are monitored. In an attempt to identify the sole effect of temperature cycles and to avoid any other biasing effects such as thermal contamination that can possibly corrupt measurements, resonance frequency measurements of the specimens are taken using an automated non-contact resonance method. The resonance frequency measurements are based on the fundamental axially symmetric mode of vibration. A hysteretic effect is observed on the measured resonance frequencies of the specimens with an application of cyclic cooling and heating. Lower stiffness moduli are obtained during the heating phase of a complete cooling and heating cycle. The stiffness moduli are calculated from measured resonance frequencies of the specimens in order to show their relative reductions due to the hysteretic effect. This finding is particularly important since it enables us to observe and understand the effect of the thermal history of asphalt concrete with regards to the reversibility behavior of its stiffness modulus. The damping of the specimens is also calculated from the measured resonance frequencies at the temperatures within the applied cyclic cooling and heating. Their observed behavior is also discussed with respect to a presence of potential micro damage.
\end{abstract}

Keywords: Non-contact resonance testing, dynamic modulus, asphalt concrete, resonance frequency

\section{Introduction}

Investigation of low temperature behaviors of asphalt concrete is of major importance since asphalt pavements in cold regions are subjected to several months of very low temperatures each year in their service lives. It is believed that the excessive brittleness of asphalt, caused by increased stiffness at low temperatures and its inability to relax stress, lead to a buildup of thermally induced stress that is responsible for cracking of pavements $[1,2]$. It is also conceivable that cyclic thermal variations may cause fatigue to asphalt concrete pavements and make them more susceptible to distress under proceeding thermal or traffic-induced stresses [3, 4]. This thermally induced fatigue distress can be manifested by a reduction in stiffness as the cyclic temperature variations continue [3]. Such a distress ultimately will lead to a lesser service life for asphalt concrete pavements and results in a costly maintenance needs.

Previous studies regarding the behavior of asphalt concrete at low temperatures focus mainly on either determining thermal stresses or fracture temperatures. Thermal stress restrained specimen test (TSRST) is utilized in order to show that low temperature cracking occurs when cyclic temperature variations coincide with the effect of aging [5, 6].Statistically significant relations between rheological characteristics of bitumen and TSRST fracture temperatures of asphalt concrete were also established in order to show the influence of bitumen properties on low temperature performance of asphalt pavements [7]. Coefficient of thermal expansion/contraction and glass transition temperature were shown to have the most influence on the rate and trend of thermal stress build up by using asphalt thermal cracking analyzer (ATCA) [8] An improved and simpler apparatus (asphalt concrete cracking device, ACCD) has also been developed in recent studies for measuring thermal stress in asphalt concrete due to low temperatures and can replace TSRST [9] Bending beam creep test has been utilized to evaluate the low temperature performance of asphalt mixtures and a regression analysis 
showed that bending beam rheometer (BBR) tests solely on bitumen are insufficient for comprehensive low temperature performance analysis [10].

The effect of isothermal low temperature conditioning or physical hardening has also been considered in studies of low temperature behavior of asphalt [11-13]. This time dependent behavior has an effect of increasing stiffness modulus of asphalt concrete due to free volume shrinkage within binder [14]

In an effort to investigate the effect of low temperature isothermal conditioning on asphalt, Behnia and Buttlar [15] have performed X-ray computer micro-tomography on an asphalt concrete specimen that has been conditioned at $-40^{\circ} \mathrm{C}$ for 2 hours. This and another related study by El Hussien and coworkers[16] on damage associated with low temperature depict the presence of micro-cracks at the aggregate-mastic interfaces as well as within the mastic portion of asphalt concrete after it has been subjected to low temperatures. Another approach, which has not been reflected considerably in the literature, explains low temperature fatigue damage as an effect of thermal cycling and thermal fatigue failure $[3,17]$. This approach considers effects of temperature variation during the day-night temperature cycles and seasonal variations on asphalt pavement.

Pavement temperatures tend to form cyclic variations by which they decrease during night and increase during the day. This can lead to an accumulation of thermal fatigue damage that has a potential of deteriorating the pavement $[3,17]$. In most of the conventional dynamic modulus tests carried out to determine low temperature performance of asphalt concrete, the effects of repeated cyclic conditioning are not considered and that can lead to an overestimation of mechanical parameters. This lack of attention to the effects of repeated low temperature cycles on their behavior could also be one of the reasons that asphalt mixtures produced by nearly identical recipes regularly behave differently in the field as compared to their performances in the lab [18]. In addition, the majority of previous studies on low temperature behaviors concentrated mainly on characterization of binders rather than mixtures. Hence, there is a need of laboratory test methods that can include the effects of repeated cyclic temperature variations on asphalt mixtures.

In this paper a new automated non-contact method of resonance frequency measurement is utilized to investigate effects of cooling and heating cycles on three different asphalt concrete specimens. This automated approach makes it possible to monitor the changes in stiffness modulus at different conditioning temperatures without an involvement of any other biasing effects and thermal disturbances. A hysteretic behavior of stiffness moduli is observed after the specimens were subjected to cyclic cooling and heating of a stepwise increase and decrease of temperature. This observed hysteretic effect is presented considering reversibility of stiffness moduli of the specimens after being subjected to cyclic thermal variations. A comparison of stiffness moduli in the cooling phase against stiffness moduli in the heating phase shows that the obtained moduli in the heating phase are lower than their corresponding values in the cooling phase. These relative reductions are calculated at temperatures of $-10{ }^{\circ} \mathrm{C},-20{ }^{\circ} \mathrm{C}$ and $-30{ }^{\circ} \mathrm{C}$. Damping ratios computed from measured resonance frequencies show increase in all the tested specimens as their temperature decreases from $-30{ }^{\circ} \mathrm{C}$ to -40 ${ }^{\circ} \mathrm{C}$. This increase in damping ratios in combination with the observed stiffness reductions are also presented with respects to a possible presence of low temperature micro-damage.

\section{Material and Methodology}

\subsection{Material}

Three disc shaped asphalt concrete specimens of $100 \mathrm{~mm}$ diameter and $20 \mathrm{~mm}$ thickness are used in this study. The geometry of the specimens was decided based on the general recommendation of length to nominal maximum aggregate size ratio of 1.5 [19].All the three specimens were made of dense graded mixes specified in Swedish standard with two of them as ABT-11, and the third one as ABS-11. ABS mix has a relatively coarser gradation than ABT mix. Table 1 shows the mixture parameters of the three mixes used in this study. The description of the specimens' aggregate gradation is presented in table 2 . 
Table 1. Mixture parameters of the three mixes of specimens

\begin{tabular}{cccc}
\hline \hline Mixture & $\begin{array}{c}\text { Bitumen content } \\
(\%)\end{array}$ & $\begin{array}{c}\text { Bitumen Penetration } \\
\text { Grade }\end{array}$ & $\begin{array}{c}\text { Air Void Ratio } \\
(\%)\end{array}$ \\
\hline \hline ABT-11-70/100 & 5.9 & $70 / 100$ & 2.6 \\
ABS-11-70/100 & 6.4 & $70 / 100$ & 2.2 \\
ABT-11-160/2200 & 6.4 & $160 / 220$ & 2.1 \\
\hline \hline
\end{tabular}

Table 2. Gradation of the three mixtures used to prepare test specimens

\begin{tabular}{lccccccccccc}
\hline \hline Sieve size (mm) & 0.063 & 0.125 & 0.25 & 0.5 & 1 & 2 & 4 & 5.6 & 8 & 11.2 & 16 \\
\hline & Passing $(\%)$ & & & & & & & & & & \\
\hline ABT-11 70/100 & 8.7 & 12 & 18 & 23 & 28 & 38 & 53 & 64 & 79 & 99 & 100 \\
\hline ABT-11 160/220 & 8.9 & 13 & 19 & 24 & 29 & 39 & 53 & 66 & 81 & 98 & 100 \\
\hline ABS-11 70/100 & 9.1 & 12 & 14 & 17 & 19 & 23 & 25 & 29 & 41 & 94 & 100 \\
\hline \hline
\end{tabular}

\subsection{Automated non-contact resonance testing}

Common reasons of measuring the frequency response of civil engineering materials after an excitation include determining the natural frequencies, relevant damping and elastic or viscoelastic parameters. The waves in a solid generated by an external excitation source can interfere and create standing waves if the input can provide energy to the frequency that is equal to the solids natural frequency. The phenomena when the input wave frequencies equal the natural frequencies of the solid are called resonance. Solid materials, in which standing waves can be generated, have several resonance frequencies corresponding to their modes of vibration. These resonance frequencies depend on the elastic or viscoelastic constants, the density, the geometry and the boundary conditions of the material. Hence elastic/viscoelastic constants of materials can be calculated based on their measured resonance frequencies.

The application of manual contact methods for resonance measurements has been frequently utilized in the field of civil engineering [20-23]. The generation of signals by these manual contact methods is achieved mostly by using impact hammers or steel balls. But as in the application of other NDTs in the field, some limitations of impact methods of resonance measurement have been encountered. These limitations are particularly related to coupling effects resulting lower signal to noise ratio as well as lack of automation [24]. These short comings have become motivations to develop non-contact methods of excitation for resonance testing.

The method of resonance frequency measurement used in this work involves frequency response of asphalt concrete specimens after an automated non-contact excitation using a loud speaker. This automated technique principally measures the frequency response of the fundamental axially symmetric mode of the specimen. The test set up used in this work also facilitates taking measurements in a controlled environment since the specimen is kept inside an environmental chamber while it is being excited. In a manual measurement using an impact hammer, there are thermal disturbances due to the opening of the environmental chamber to perform the impact. The methodology and procedures for determining modulus from measured resonance frequencies has been described in detail in [25] and [27]. 

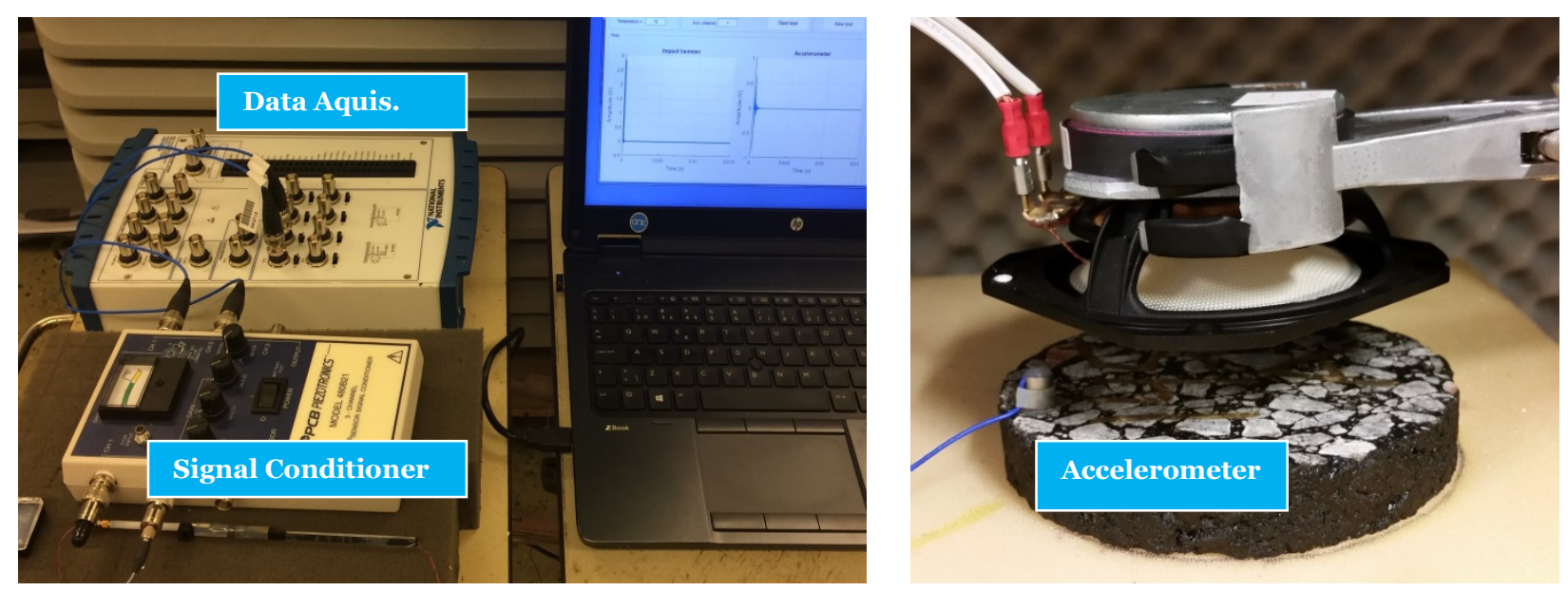

Figure 1. Experimental set up of the automated non-contact method of resonance frequency measurement

An automated method of resonance measurement using a loud speaker as a source of excitation is used by sending out a sinusoidal signal to the asphalt concrete specimens. The test equipment includes a loudspeaker (Seas Prestige 17TDFC/TV H1210). The chirp function in MATLAB is used to send a 10 $\mathrm{s}$ long chirp. By slowly increasing the frequency of the signal from $8 \mathrm{kHz}$ to $12 \mathrm{kHz}$, a sweep is applied to the specimen. The test frequency range should be set to include the expected resonance frequency of the specimen. It is selected based on typical results or a similar trial test by using impact hammer on specimens of similar geometry. The output channel of a National Instruments data acquisition device (NI USB-6251 M series) is used to transmit the signals to the loudspeaker. A signal conditioner (PCB model 480B21) is used to amplify the accelerometer signal. The sampling frequency of the signal sweep is selected to be100 kHz. An accelerometer (PCB model 352B10) with an operating temperature range of $-54{ }^{\circ} \mathrm{C}$ to $121{ }^{\circ} \mathrm{C}$ is attached to the samples and the data is acquired through the data acquisition device and output to a computer. The samples are set up inside a thermal chamber on soft foam to achieve free boundary conditions. The measurement control system is suitable for avoiding thermal disturbances that are associated with opening of the environmental chamber. Figure 1 shows the components of the experimental set up. Figure 2a shows an example of a measured dynamic response of a specimen during the frequency sweep excitation by a loud speaker. The corresponding frequency response function is also shown in figure $2 \mathrm{~b}$.

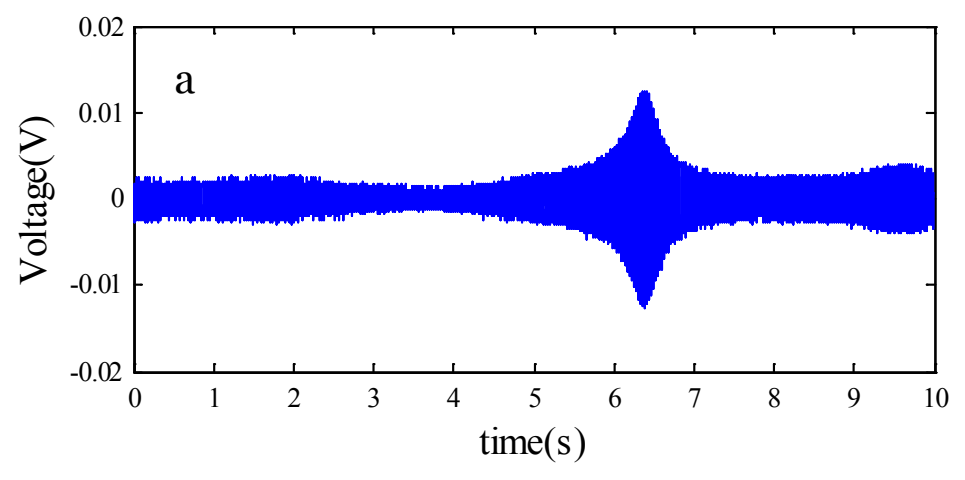




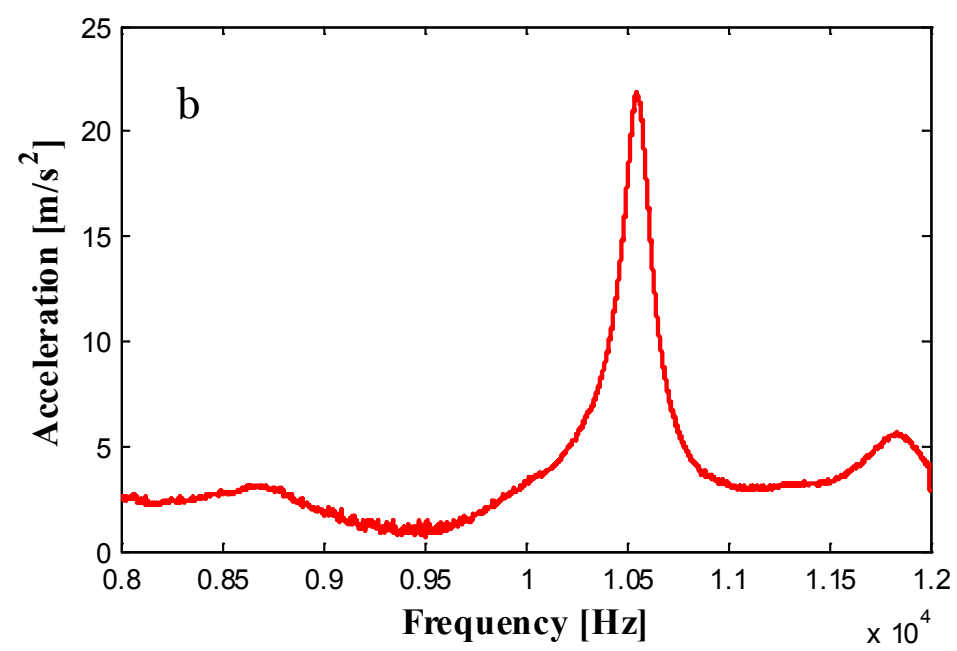

Figure 2. A measured dynamic response of an asphalt concrete specimen in time domain (a) and the corresponding frequency spectrum (b)

\section{Testing program for cyclic temperature applications}

The experiment protocol of this study is planned in such a way that effects of a decrease in temperature as well as repeated cycles of cooling and heating on asphalt concrete can be monitored The measurement of resonance frequencies of the specimens are carried out by applying cyclic cooling with a stepwise thermal stage. The samples are conditioned for 4 hours at every stage of measurement within the cycles. Figure 3 shows the test program with just two of the four cycles applied to each specimen. The remaining two cycles are also applied in a similar fashion.

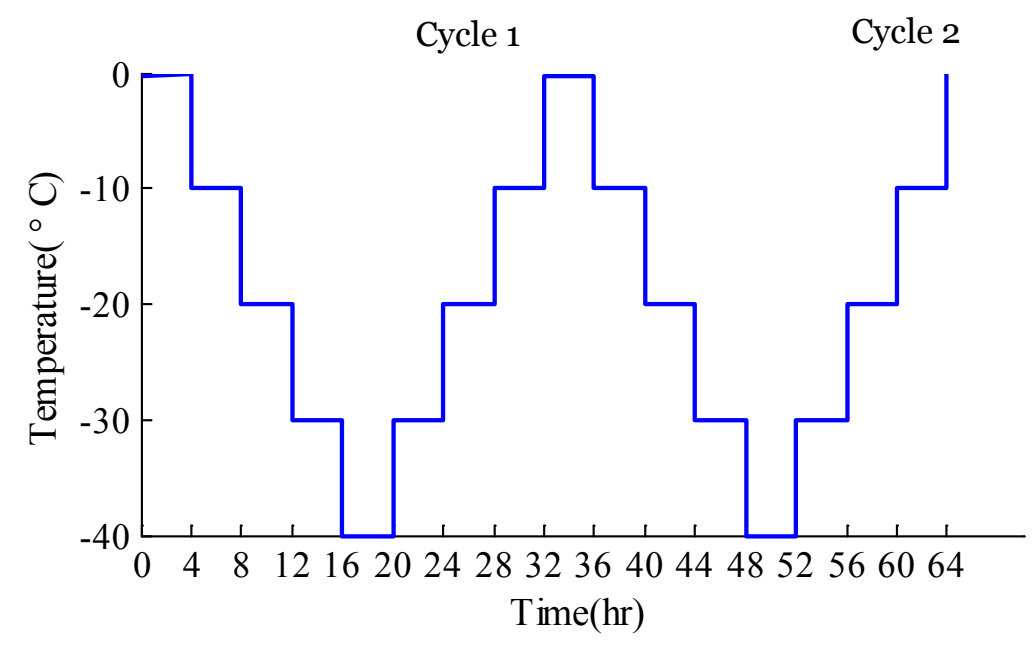

Figure 3. Applied cyclic temperatures for resonance frequency measurements

\section{Stiffness modulus calculation}

The measured resonance frequencies are first converted to undamped natural frequencies $\left(f_{n}\right)$ using the half power bandwidth method. Stiffness modulus is determined from the geometry parameters and a dimensionless parameter $\left(\omega_{n}\right)$ as in equation 1and 2 . The method of determining parameter in equation 1 from measured resonance frequencies is explained in detail in [25] and [27]. 


$$
G=\frac{4 \pi^{2} f_{n}^{2} R_{o}^{2} \rho}{\Omega_{n}^{2}}
$$

where $f_{n}$ is the natural frequency and Ro is the radius of the specimen, $\rho$ is its density and $\mathrm{G}$ is the shear modulus. For a specimen of specified geometric parameters and measured density, the nondimensional frequency parameter is obtained by performing eigenmode analysis and the stiffness modulus is calculated based on the procedures presented in $[25,27]$ and equations 2 and 3.

$$
\begin{aligned}
& E=2 G *(v+1) \\
& E^{*}=E^{\prime}+i E^{\prime \prime}=E^{\prime}(1+i \xi / 2) \\
& \xi=\frac{\Delta f}{2 f_{d}}
\end{aligned}
$$

In determining complex dynamic modulus, damping is considered by using the half power bandwidth method where in equation 3 and $4, \xi$ is damping ratio, $\Delta f$ calculated from resonance frequency curve at 0.707 times the pick amplitude and $f_{d}$ is the measured damped resonance frequency. Poisson's ratios of 0.25 and 0.2 are assumed for temperatures above $-20{ }^{\circ} \mathrm{C}$ and for temperatures below $-20{ }^{\circ} \mathrm{C}$ respectively based on literatures [30].

\section{Results and Discussion}

The experimental protocol of this study is organized to be able to investigate the effects of a decrease in temperature as well as repeated cycles of cooling and heating on asphalt concrete stiffness modulus. The method's applicability is thoroughly investigated in $[25,31]$ and results showed very good repeatability and reproducibility. As expected the measured resonance frequencies, which are functions of stiffness moduli, keep increasing with a decrease in temperature. An example of frequency spectra from multiple temperatures is shown in figure 4. It can be noted from this result that the resonance curves become narrower and higher in amplitude with decrease in temperature. This is a manifestation of the change in the visco-elastic behavior of asphalt concrete with a decrease in temperature. The loss of the complex dynamic modulus becomes less and the specimens become more elastic with a decrease in temperature.

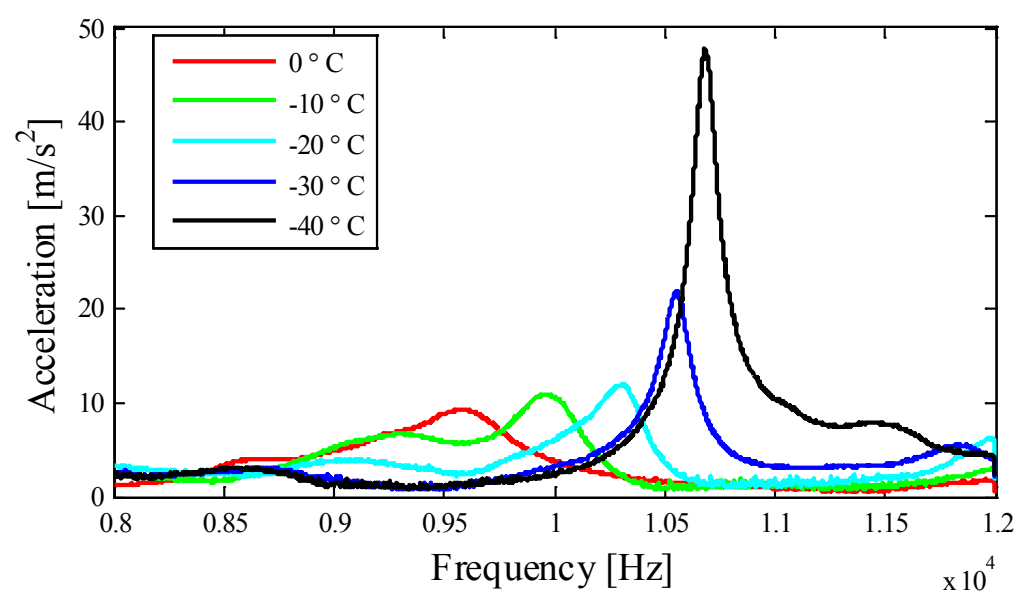

Figure 4. Examples of measured resonance frequencies of an asphalt concrete sample at multiple temperatures

The resonance frequency measurements were carried out on all the three specimens at temperatures of $0{ }^{\circ} \mathrm{C},-10{ }^{\circ} \mathrm{C},-20^{\circ} \mathrm{C},-30{ }^{\circ} \mathrm{C}$ and $-40{ }^{\circ} \mathrm{C}$ in decreasing order and consequently in reverse order forming a complete cooling and heating cycle. The samples were kept at each temperature for 4 hours before 
each measurement is taken and four such cycles are applied to all the specimens. This cyclic measurement is denoted in this work by thermal loading (cooling) and thermal unloading (heating).

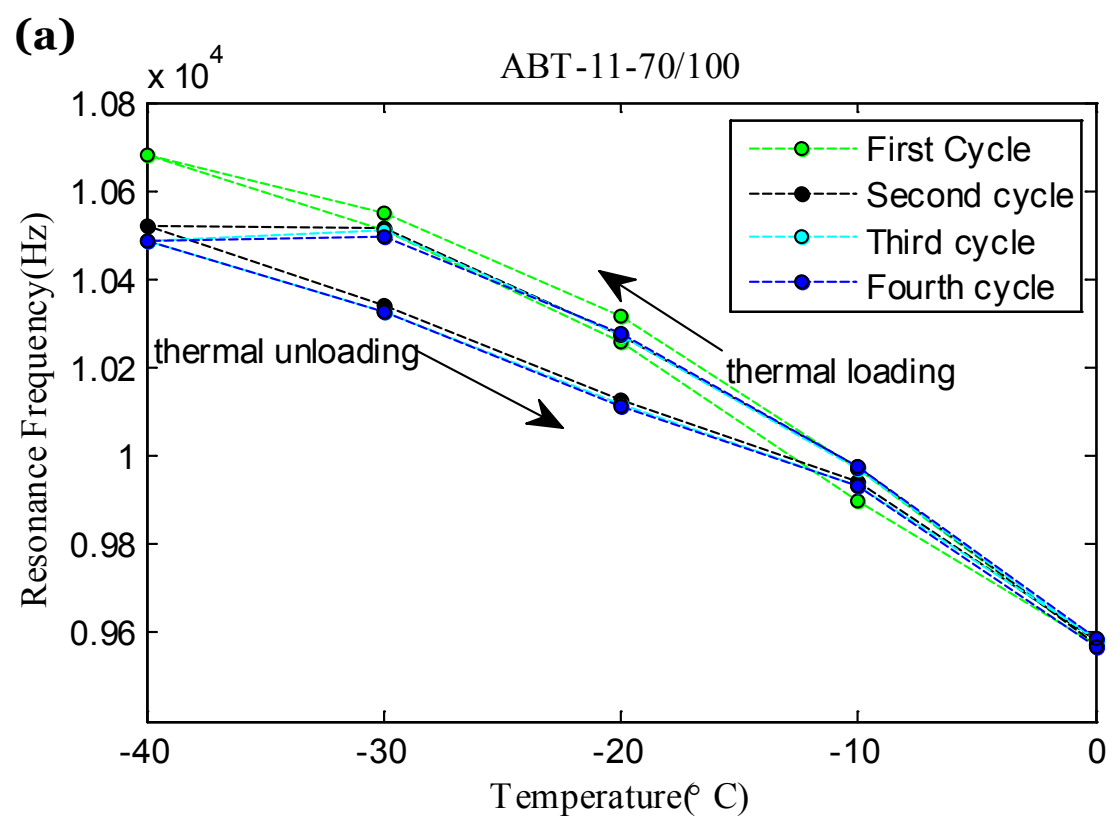

(b)

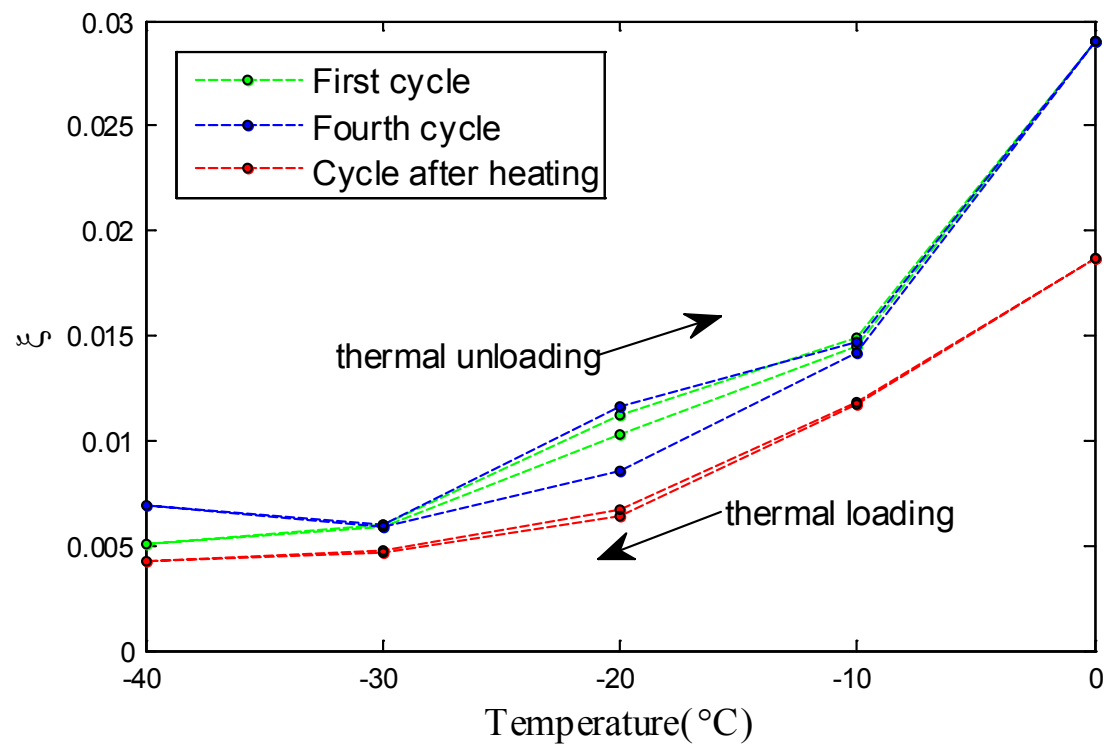

Figure 5(a) Hysteretic behavior of measured resonance frequencies due to repeated applications of cooling and heating cycles to specimen ABT-11-70/100 and (b) Damping ratios of ABT-11-70/100 computed from measured resonance frequencies in the first and fourth cycles and a cycle after specimen heating

Figure 5(a) shows the behavior of measured resonance frequencies of the ABT-11-70/100 specimen from the four repeated cooling and heating cycles. The first cycle was applied on the sample that was kept at ambient temperature and was not exposed to any other form of stress or damage. In the first thermal unloading phase, the temperature is increased from $-40^{\circ} \mathrm{C}$ to the starting measurement temperature $\left(0^{\circ} \mathrm{C}\right)$ with $10^{\circ} \mathrm{C}$ step-wise decrement. In this phase, a noticeable reduction of the resonance frequencies is observed at the intermediate temperatures $\left(-30{ }^{\circ} \mathrm{C},-20^{\circ} \mathrm{C}\right.$ and $\left.-10{ }^{\circ} \mathrm{C}\right)$ as compared to the corresponding values in the thermal loading phase. 


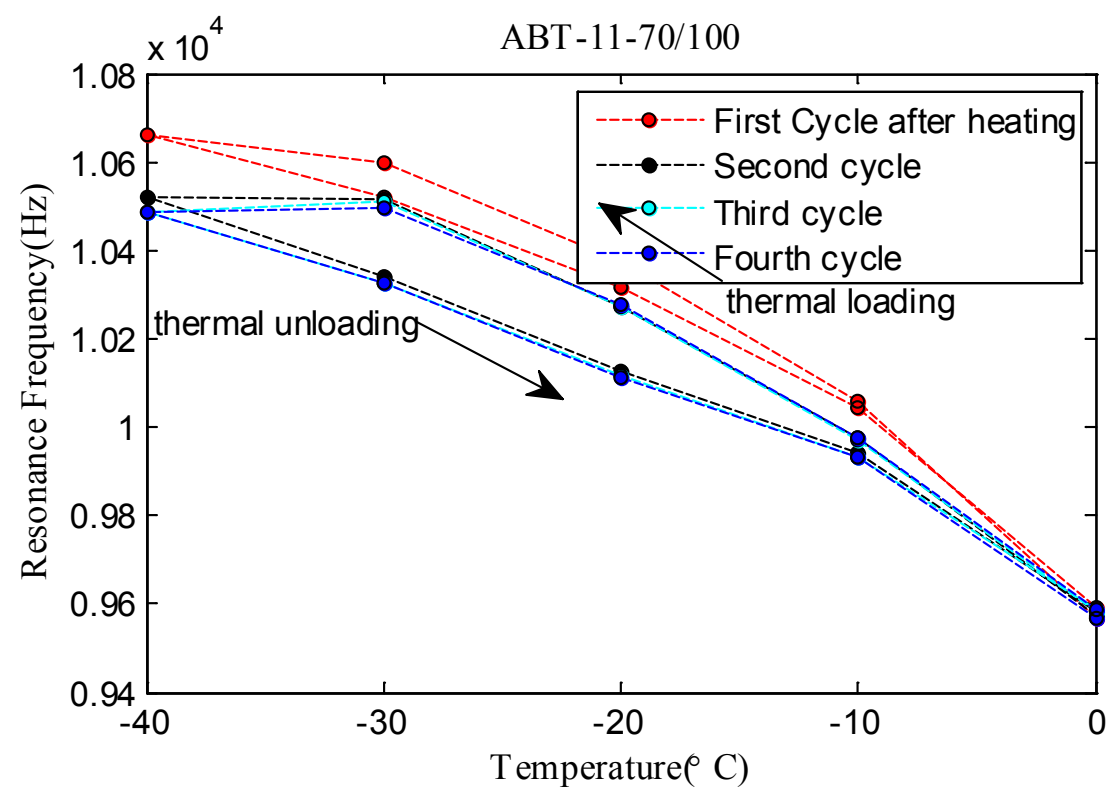

Figure 6. Effect of heating at $40{ }^{\circ} \mathrm{C}$ after application of repeated cycles on asphalt concrete specimen ABT-11-70/100

It can be observed that the first cycle has less effect on the reduction of the measured resonance frequencies during the thermal unloading stage as compared to the proceeding cycles. Three more cycles were applied with the same procedure and the results indicate that all the cycles have the same effect of reducing modulus in the thermal unloading phase with a more significant increase in the second to fourth cycles.

In order to see the effect of heating on the observed hysteretic behavior, the samples are heated to 40 ${ }^{\circ} \mathrm{C}$ for 4 hours and allowed to cool down to ambient temperature for 24 hours. The same measurements as before were performed on the sample by decreasing and then increasing temperature for a full cycle.

Figure 6 shows a comparison of the repeated cycles and a cycle after the sample is heated. We can observe that the cycle after the heating has similar behavior as the first cycle in Figure 5 in such a way that both cycles exhibit considerably less reductions in resonance frequencies in their corresponding thermal unloading phases as compared to the consequent cycles $(1.05 \%$ before heating and $1.13 \%$ after heating at $-20{ }^{\circ} \mathrm{C} ; 0.7 \%$ before heating and $1.45 \%$ after heating at $-30{ }^{\circ} \mathrm{C}$ ).

Stiffness moduli are computed based on the measured resonance frequencies as per the procedure described in section 4. An increase in the stiffness moduli is shown in Figure 7 during the thermal loading phase with the step-wise decrease in temperature. This is the expected behavior due to its viscoelastic behavior at low temperatures. However, the thermal unloading phase has shown a tendency of forming hysteretic loop as the temperature goes back to $0^{\circ} \mathrm{C}$. It is expected that increase in temperature decreases modulus. However, the moduli at the intermediate measurement temperatures ($30{ }^{\circ} \mathrm{C},-20{ }^{\circ} \mathrm{C}$ and $-10{ }^{\circ} \mathrm{C}$ ) decrease during the unloading phase as compared to the corresponding values at the same temperatures during the thermal loading phase. 


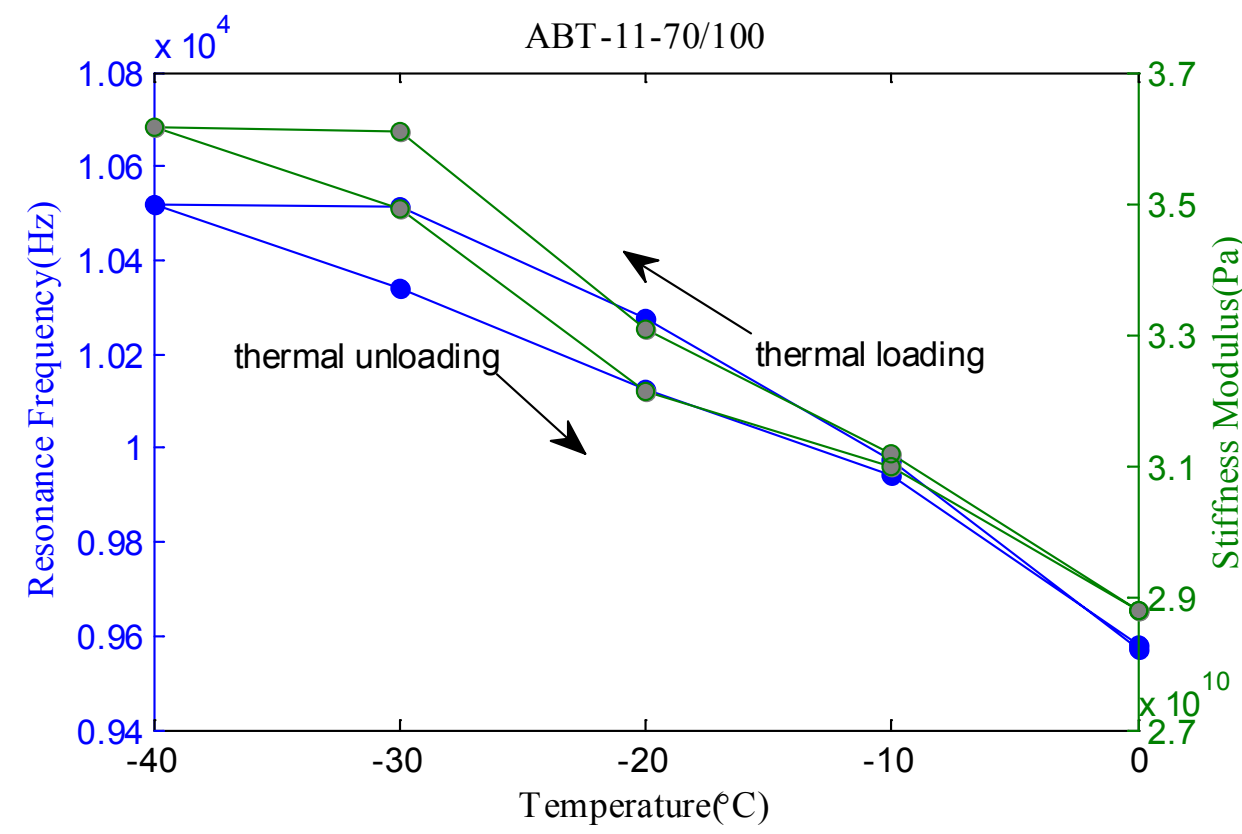

Figure 7. Stiffness moduli of ABT-11-70/100 computed from corresponding measured resonance frequencies of fourth cycle

In order to see whether this hysteretic behavior is manifested on other mixes of asphalt as well, the same procedure of application of cyclic temperature loading was carried out on two more specimens (ABS-11-70/100 and ABT-11-160/220). A more significant reduction in measured resonance frequency was obtained for ABS-11-70/100 as it is shown in Figure 8. It is also particularly noticeable in this result that there is a reduction in resonance frequency when temperature decreased further from $-30{ }^{\circ} \mathrm{C}-40{ }^{\circ} \mathrm{C}$.

The hysteretic behavior is furthermore observed on a third sample (ABT-11-160/220) as shown in Figure 9(a). In this case, the hysteresis loops have relatively smaller $(<1.4 \%)$ reductions of resonance frequencies in the thermal unloading phase until the fourth cycle is reached. It is reasonable to assume that since the binder used in this mixture is softer, this specimen can withstand more thermal fatigue in terms of stiffness variations than the stiffer binder mixtures in the previous specimens.

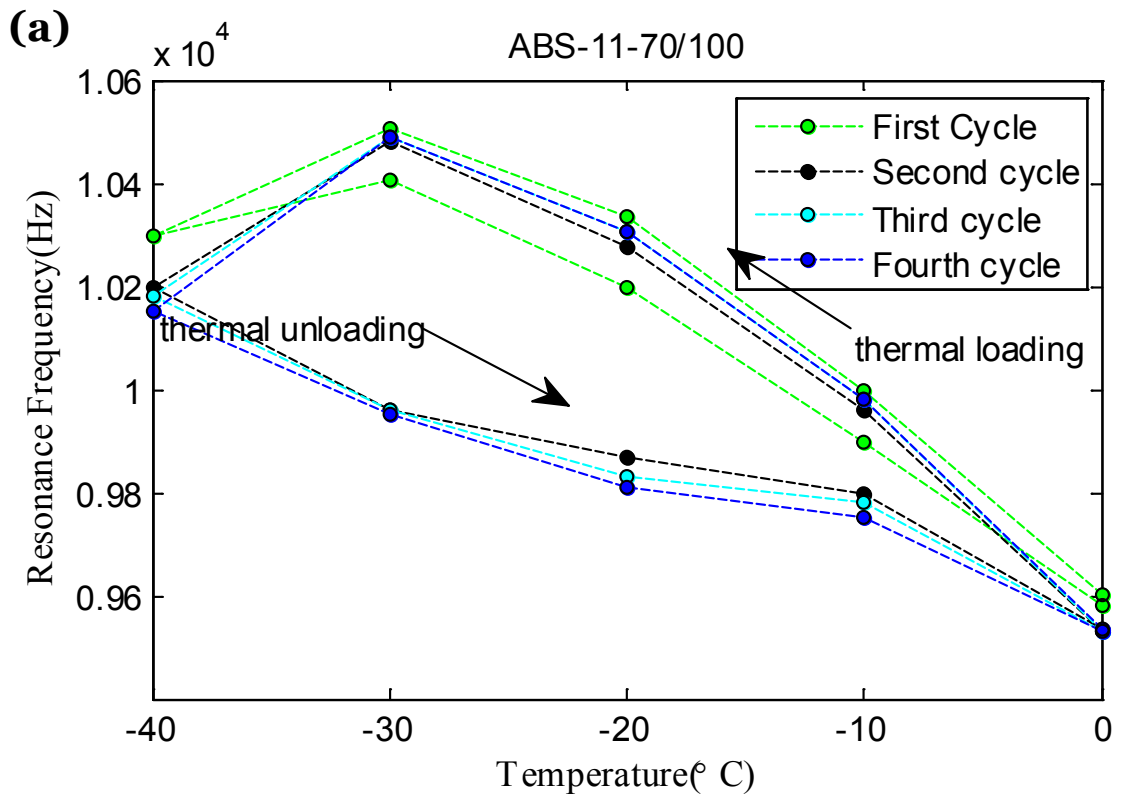




\section{(b)}

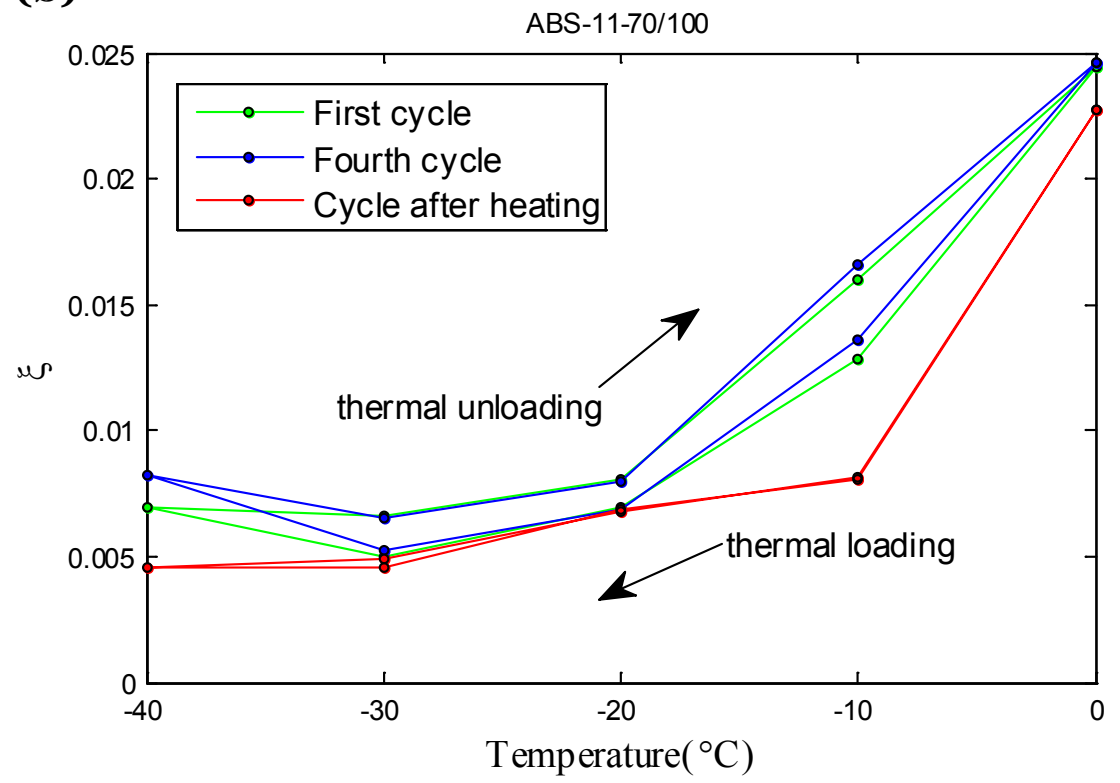

Figure 8.(a) Hysteretic behavior of measured resonance frequencies due to cooling and heating cycles on sample ABS-11-70/100 (b) Damping ratios computed from measured resonance frequencies of ABS-11-70/100 in the first and fourth applied cycles and a cycle after specimen heating

Resonance frequency spectra from the tests were used to compute damping ratios $(\xi)$ of the specimens based on the half-power bandwidth method as in equation 4 and with respect to the applied cyclic thermal cooling. Figure 5(b), 8(b) and 9(b) present the behaviors of the damping ratios of the specimens for the first, the last and the cycles after heating specimens to $40{ }^{\circ} \mathrm{C}$. These cycles are selected since they can be taken as reference cycles in studying their evolving behavior and also the plots become clearer with only selected cycles. An increase in damping is observed in all the specimens when temperature decreases from $-30{ }^{\circ} \mathrm{C}$ to $-40{ }^{\circ} \mathrm{C}$ (Figure $5(\mathrm{~b}), 8(\mathrm{~b})$ and $9(\mathrm{~b})$ ). The normal expectation is that damping should decrease due to a more elastic behavior as temperature decreases. An increase in damping is also observed in the thermal unloading phases within cycles. The hysteretic behavior is observed more predominantly in ABS-11-70/100

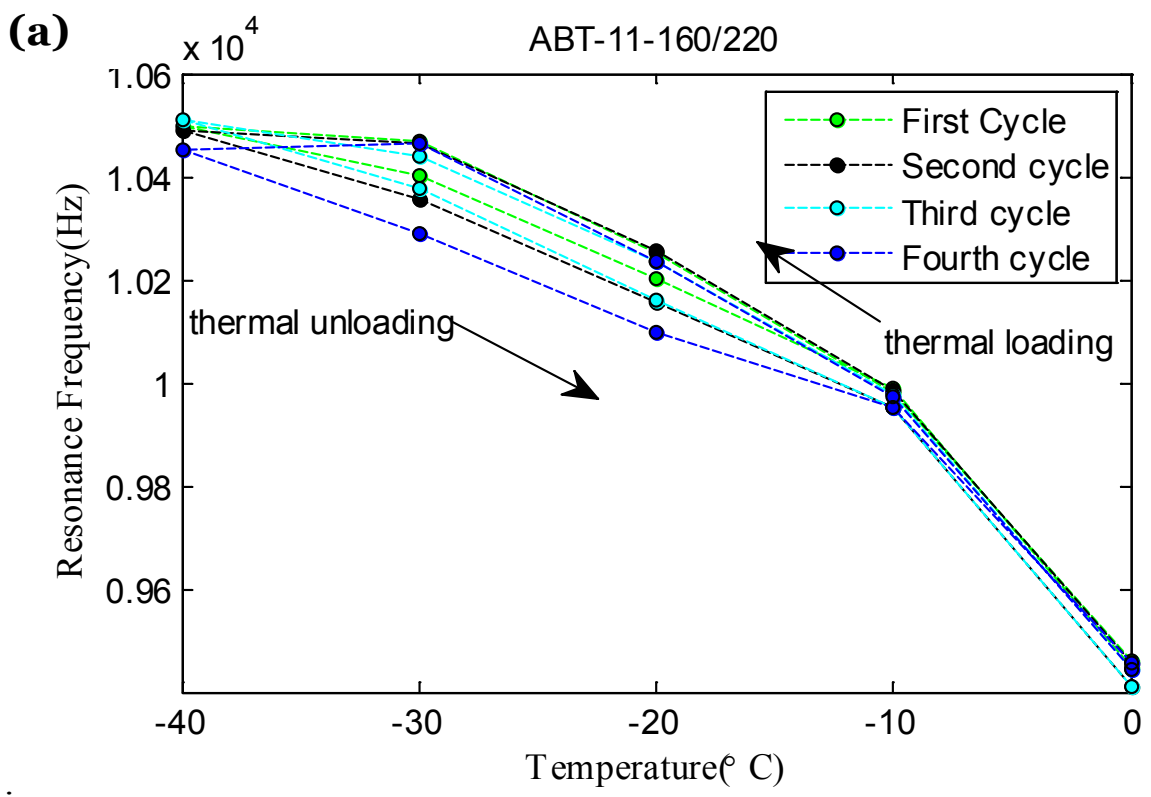




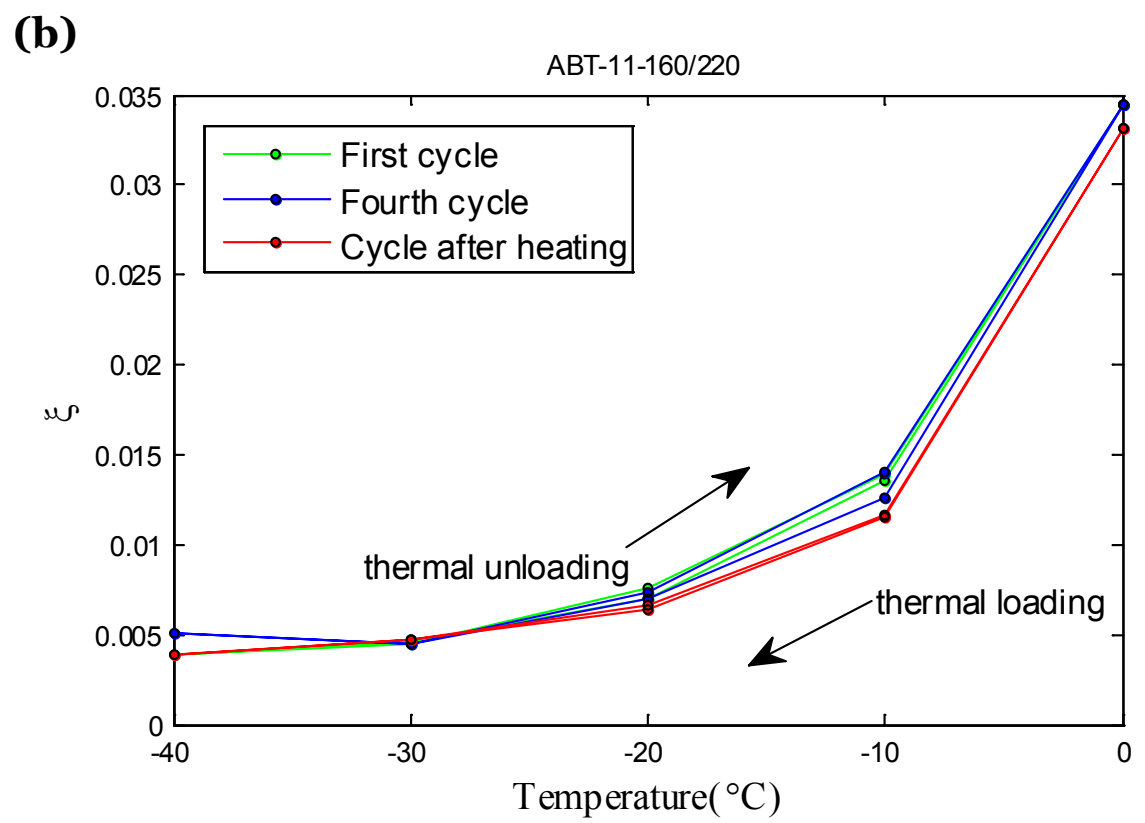

Figure 9a. Hysteretic behavior of measured resonance frequencies due to cooling cycles on sample ABT-11-160/220. (b) Damping ratios computed from measured resonance frequencies of ABT-11160/220 in the first and fourth applied cycles and a cycle after specimen heating

A study of the behavior of damping with regards to micro damage is more reliable as compared to monitoring stiffness modulus since damping variations associated with dissipated energy are more sensitive to damage than stiffness variations $[26,28]$.The results of our study also show an indication of micro damage as a combination of stiffness reduction and increase in damping at temperatures below $-30{ }^{\circ} \mathrm{C}$ with cyclic thermal loading and unloading. Moreover, no such increase in damping ratios is observed after the specimens were heated and tested again on a first cycle (Figure 5(b), 8(b) and $9(b))$.This suggests that the number of cycles has also an effect on the observed behavior.

Figure 10 shows a comparison of the reductions in stiffness modulus of the three specimens in the thermal unloading phases at the same temperatures. We can be able to observe that the reduction keeps increasing as the measurement temperature decreases for samples ABT-11-70/100 and ABS-11$70 / 100$. The ABT-11-160/220 specimen shows smaller reductions at all temperatures as compared to the other two specimens which are likely caused by the above mentioned reason.

It is to be noted that the purpose of this calculation is to illustrate the relative reduction in stiffness modulus due to the applied cyclic thermal cooling and Poisson's ratios of 0.25 and 0.2 are assumed for temperatures above $-20{ }^{\circ} \mathrm{C}$ and for temperatures below $-20{ }^{\circ} \mathrm{C}$ respectively based on literatures.

Besides the reductions observed in the thermal unloading phase at temperatures of $-10{ }^{\circ} \mathrm{C},-20^{\circ} \mathrm{C}$ and $-30^{\circ} \mathrm{C}$ within the cooling and heating cycles, a tendency of slight decrease can also be noticed at -40 ${ }^{\circ} \mathrm{C}$ in all the specimens as the number of cycles increases. This can be attributed to thermal fatigue accumulation associated with micro damage in the specimens due to relative thermal contraction and expansion between mastic and aggregates 


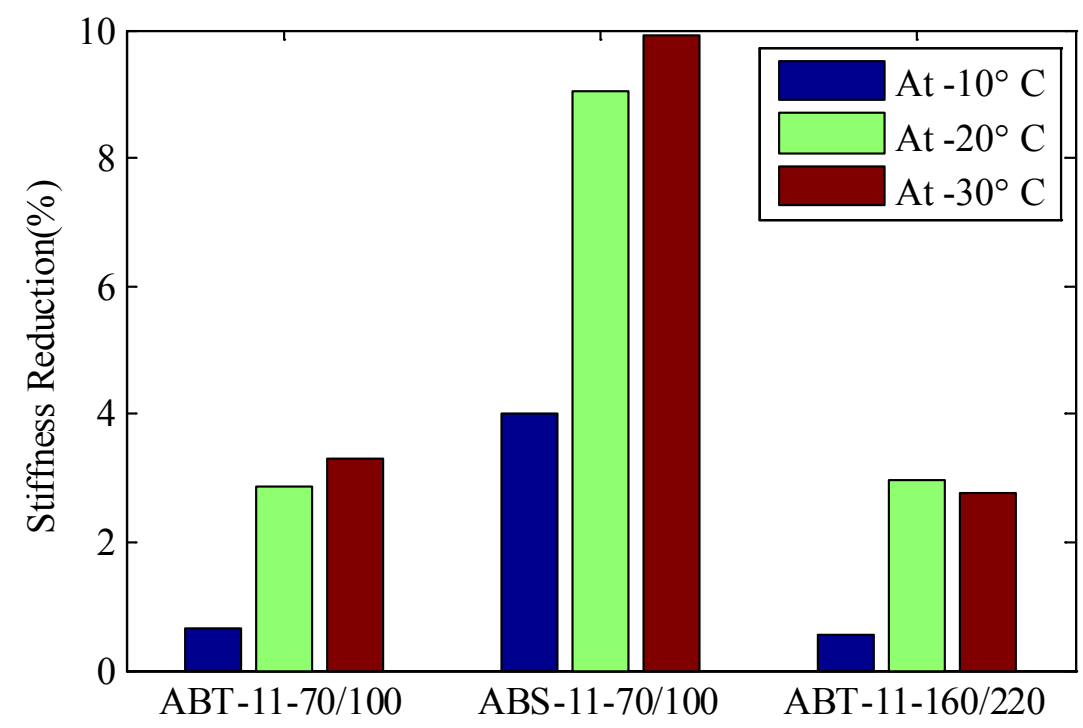

Figure 10. Reduction in the stiffness modulus of the tested specimens due to thermal loading and unloading

Table 3 shows the measured resonance frequencies of every cycle applied to all the three specimens. It can also be noted that the effect of heating the specimens at $40^{\circ} \mathrm{C}$ on the measured resonance frequencies of ABS-11 70/100 and ABT-11 160/220 is less as compared to that of ABT-11 70/100

Table 3. Measured resonance frequencies $(\mathrm{Hz})$ with application of cyclic cooling and heating. N.B The second row in each cycle represents the thermal unloading phase.

\begin{tabular}{|c|c|c|c|c|c|c|}
\hline Sample & $\mathbf{C y c l e s}$ & $\mathbf{0}^{\mathbf{}} \mathbf{C}$ & $-\mathbf{1 0}^{\mathbf{}} \mathbf{C}$ & $-\mathbf{2 0}^{\mathbf{}} \mathbf{C}$ & $-\mathbf{3 0}^{\mathbf{}} \mathbf{C}$ & $-\mathbf{4 0}^{\mathbf{}} \mathbf{C}$ \\
\hline ABT-11 70/100 & 1 & 9611 & 9972.2 & 10311 & 10551 & 10683 \\
\hline & & 9601.2 & 9964 & 10257 & 10514 & \\
\hline & 2 & 9617.1 & 9979.9 & 10280 & 10512 & 10520 \\
\hline & & 9609.2 & 9943.9 & 10127 & 10339 & \\
\hline & & 9611.9 & 9969.4 & 10267 & 10510 & 10481 \\
\hline & 4 & 9610.2 & 9932.7 & 10115 & 10321 & \\
\hline & & 9609.1 & 9977.5 & 10282 & 10487 & 10486 \\
\hline & After heat & 9620 & 10059 & 10361 & 10598 & 10660 \\
\hline & & 9619.2 & 10045 & 10318 & 10521 & \\
\hline ABS-11 70/98 & 1 & 9624.2 & 9997 & 10336 & 10508 & 10296 \\
\hline & & 9620 & 9897 & 10204 & 10391 & \\
\hline & 2 & 9549.4 & 9983.2 & 10308 & 10494 & 10180 \\
\hline & & 9541 & 9798.7 & 9959.5 & 9949.3 & \\
\hline & 3 & 9549.4 & 9961.7 & 10278 & 10482 & 10157 \\
\hline & & 9545 & 9780.4 & 9831.1 & 9960 & \\
\hline & 4 & 9549 & 9961.7 & 10278 & 10482 & 10089 \\
\hline & & 9547 & 9753.4 & 9804.8 & 9960 & \\
\hline & After heat & 9563 & 9938 & 10274 & 10477 & 10221 \\
\hline & & 9555 & 9803 & 10107 & 10183 & \\
\hline & 1 & 9453.4 & 9980.2 & 10251.7 & 10470.6 & 10497 \\
\hline & & 9450.6 & 9983.1 & 10203.1 & 10400.4 & \\
\hline
\end{tabular}




\begin{tabular}{|l|c|c|c|c|c|c|} 
& 2 & 9451.4 & 9977.5 & 10233 & 10464.8 & 10489 \\
\hline & & 9448.8 & 9949.2 & 10167.7 & 10361.2 & \\
\hline & 3 & 9439.2 & 9977.4 & 10237.5 & 10438 & 10491 \\
\hline & & 9431.1 & 9950.1 & 10160 & 10377.2 & \\
\hline & 4 & 9453.9 & 9974 & 10234.9 & 10467 & 10449 \\
\hline & & 9450.1 & 9963.4 & 10099 & 10291.3 & \\
\hline & After heat & 9449.4 & 9970.8 & 10231.3 & 10453.5 & 10497 \\
\hline & & 9439.7 & 9971.1 & 10181.4 & 10381.4 & \\
\hline
\end{tabular}

\section{Discussion}

ABS-11-70/100 is a coarse graded mix with higher binder content than ABT-11-70/100 as it is shown in table 2. Asphalt mixtures with coarse gradations are more susceptible to low temperature micro damage associated with differential thermal contraction between aggregates and mastic [29]. This may result in a lower stiffness modulus that is attributed to low temperature micro damage and it can be the reason that the ABS 11-70/100 specimen's modulus shows a more pronounced decrease than the other samples and its modulus also lower at $-40{ }^{\circ} \mathrm{C}$ unlike the other specimen.

The presence of micro cracks is demonstrated in related studies regarding micro damage associated with thermal stress that develops after low temperature conditioning at $-30{ }^{\circ} \mathrm{C}$ and $-40{ }^{\circ} \mathrm{C}[15,16]$. Thermal fatigue caused by day and night cyclic temperature variations simulated by applying cyclic temperature on asphalt concrete was also modeled in [3] and it is found out that thermal fatigue damage keeps increasing with the number of cycles.

Without considering the thermal history of asphalt concrete, its stiffness modulus can be overestimated since it is shown in this work that reduced stiffness modulus is inevitable at the same measurement temperature but after asphalt concrete is subjected to cycles of thermal variations.

It should be noted that further studies need to be carried out in order to broaden the findings of this work by considering more number of thermal cycles, effects of longer periods under low temperature and more mixture types. The scope of the study in this paper is limited to illustrating the observed hysteretic behavior, the applicability of a new noncontact resonance testing method and the capability of modal damping together with stiffness reductions for characterizing low temperature micro damage.

\section{Conclusions}

A hysteretic behavior of measured fundamental resonance frequencies is observed after cyclic cooling and heating of three different asphalt concrete specimens of different mixes. The results indicate that stepwise cyclic low temperature conditioning of the specimens has an effect of reducing stiffness modulus (computed from measured resonance frequencies) when the thermal unloading phase of each cycle takes place. Contrary to the expectation of stiffness modulus to be reversible with increase in temperature, the results of this work have shown that there is a significant reduction in stiffness moduli at the same temperatures in the thermal unloading phase within a cyclic cooling and heating. The hysteretic behavior is more pronounced on ABS-11-70/100 specimen and a decrease in stiffness modulus is observed as the temperature was decreased from $-30{ }^{\circ} \mathrm{C}$ to $-40{ }^{\circ} \mathrm{C}$. It is also observed from the ABT-11-160/220 specimen, which is prepared from a soft binder, that the reduction in stiffness modulus was relatively minimum until the fourth cycle. These findings are particularly interesting since we can be able to observe the sole effect of only low temperature conditioning with respect to the reversibility behavior of stiffness of asphalt concrete with cyclic temperature variations. Continuous reductions in stiffness modulus are also observed at $-40{ }^{\circ} \mathrm{C}$ with increasing number of cycles applied to all the specimens The results of this work show that it is necessary to consider the thermal history of asphalt concrete for determining its stiffness modulus since reduced values are obtained at the same measurement temperature after cyclic thermal variations. 
A study of damping ratios calculated from measured resonance frequency spectrums showed increase in all the specimens as the temperature was reduced from $-30{ }^{\circ} \mathrm{C}$ to $-40{ }^{\circ} \mathrm{C}$ within the applied cooling cycles. A combination of these increases in damping ratios with stiffness reductions is regarded as a good indication of a presence of thermal micro damage.

This work also highlights the importance of a new non-contact method of resonance frequency measurement in order to investigate the effect of cooling cycles on asphalt concrete. The method used in this work makes it possible to monitor the changes in stiffness modulus of asphalt concrete specimens at low temperatures without an involvement of any other form biasing effects and with a relative ease and minimum cost. The technique also helps to avoid biasing effects such as coupling effects that arise due to contact of measuring devices and which require equipment compliance corrections in addition to helping to avoid temperature variations caused by physical contact in conventional testing methods.

\section{References}

[1] Marasteanu, M.; Zofka, A.; Turos, M.; Li, X.; Velasquez, R.; Xue, L.; Buttlar, W.; Paulino, G.; Braham, A.;Dave, E.; et al. "Investigation of Low Temperature Cracking in Asphalt Pavements."' A Transportation Pooled Fund Study; Report No MN/RC 2007-43; University of Minnesota: Minneapolis, MN, USA, 2007.

[2] Vinson, T.S.; Janoo, V.C. "'Low Temperature and Thermal Fatigue Cracking,"' Summary Report NoSR-OSU-A-003A-89-1; University of California: Berkeley, CA, USA, 1989.

[3] Md. R. Islam, "Thermal Fatigue damage of asphalt pavement," PhD Thesis, University ofNew Mexico, 2015

[4] Vinson, T. S., V. C. Janoo, and R. C. G. Haas., "Low Temperature and Thermal Fatigue Cracking," Summary Report SR-OSU-A-003A-89-1. Strategic Highway Research Program, June 1989.

[5] N. M. Jackson and T.S. Vinson, "Analysis of Thermal Fatigue Distress of Asphalt Concrete Pavements,"Jour. of the Transportation Res. Board., 2014.

[6] J.E. Kliewer, H. Zeng and Vinson T.S., "Aging and Low-Temperature Cracking of Asphalt Concrete Mixtures," Jour. Cold Regions Eng. 1996.

[7] U. Isacsson and H.Zen, "Cracking of asphalt at low temperature as related to bitumen rheology," Jour. Materials Science, 1998.

[8] H. Tabatabaee, R Velasquez and A. Arshadi, "Modeling of Asphalt Mixtures Contraction and Expansion Due to Thermal Cycling," National Pooled Fund Study-Phase II, University of Wisconsin-Madison, 2012

[9] M. Akentuna, S.Soo Kim,M. Nazzal, A.R.Abbas and M. S. Arefin, "Study of thermal stress development of asphalt mixtures using the Asphalt Concrete Cracking Device(ACCD)," Constructon and Building Materials, April 2016.

[10] M. Pszczola, M. Jaczewski, D Rys, P. Jaskula and C. Szydlowski, "Evaluation of Asphalt Mixture Low-Temperature Performance in Bending Beam Creep Test,"Materials MDPI, 2018

[11] Togunde, O.P.; Hesp, S.A.M. " Physical hardening in asphalt mixtures," Int. J. Pavement Res. Technol,2012.

[12] Judycki, J. "Influence of low-temperature physical hardening on stiffness and tensile strength of asphalt concrete and stone mastic asphalt,". Constr. Build. Mater. 2014

[13] D. A. Anderson and M.O.Marasteanu, "Physical Hardening of Asphalt Binders Relative to Their Glass Transition Temperatures,", Jour. of the Transportation Res. Board., 1999

[14] H. U. Bahia and D. A. Anderson, "Physical Hardening of Paving Grade Asphalts As Related To Compositional Characteristics," Prepr. ACS, Div. Fuel ..., vol. 37, no. 3, pp. 1397-1407, 1992

[15] B. Behnia and W. G. Buttlar, "Cooling cycle effects on low temperature cracking characteristics of asphalt concrete mixture," Materials and Structures, 2014.

[16] H. M. El Hussein, K. W. Kim and J. Ponniah, "Asphalt concrete damage associated with extreme low temperatures," J. Mater. Civ. Eng., 1998. 
[17] T.H. Wang,Li-jun Su and Ju-yun Z., "A case study on diurnal and seasonal variation in pavement temperature," Int. Jour. Pav. Eng, 2014.

[18] S. Iliuta, A. Andriescu, S. A. M. Hesp and Kai K. Tam "Field Validation Study of LowTemperature Performance Grading Tests for Asphalt Binders," Jour. of the Transportation Res. Board, 2004.

[19] L. Zhang, T. S. Li, and Y. Q. Tan, "The potential of using impact resonance test method evaluating the anti-freeze-thaw performance of asphalt mixture," Constr. Build. Mater., vol. 115 , pp. 54-61, 2016

[20] Kweon and Kim, "Determination of Asphalt Concrete Complex Modulus with Impact Resonance Test," Transp. Res. Rec. J. Transp. Res. Board Natl. Acad., pp. 151-160, 2015.

[21] A. Gudmarsson, N. Ryden, and B. Birgisson, "Application of resonant acoustic spectroscopy to asphalt concrete beams for determination of the dynamic modulus," Mater. Struct., vol. 45, no. 12, pp. 1903-1913, 2012.

[22] M. Brigante and M. A. Sumbatyan, "Acoustic methods in nondestructive testing of concrete: Review of foreign publications in the field of theoretical studies," Russ. J. Nondestruct. Test., vol. 49, no. 4, pp. 185-195, 2013.

[23] S. Mun, "Determining the Dynamic Modulus of a Viscoelastic Asphalt Mixture Using an Impact Resonance Test With Damping Effect," Res. Nondestruct. Eval., vol. 26, no. 4, pp. 189207, 2015.

[24] M. Kaczmarek, B. Piwakowski, and R. Drelich, "Noncontact Ultrasonic Nondestructive Techniques: State of the Art and Their Use in Civil Engineering," J. Infrastruct. Syst., vol. 23, 2016.

[25] A. Bekele, N. Ryden, A. Gudmarsson, and B. Birgisson, "Automated Non-Contact Resonance Excitation method of Low temperature Behaviour of Asphalt concrete,"(Under revision at JONE, 2018)

[26] D. Montalvão, N.M.M. Maia and A.M.R. Ribeiro, "A Review of Vibration-based Structural Health Monitoring with Special Emphasis on Composite Materials," The Shock and Vibration Digest 2006.

[27] G. Martinček, "The determination of poisson's ratio and the dynamic modulus of elasticity from the frequencies of natural vibration in thick circular plates," J. Sound Vib., vol. 2, no. 2, pp. 116-127, 1965

[28] M S Cao, G G Sha, Y F Ga and W Ostachowicz, "Structural damage identification using damping: a compendium of uses and features," Smart Mater. Struct. 26, 2017

[29] Moses Akentuna1 and Sang-Soo Kim, "Effects of Aggregate Thermal Contraction Properties on Asphalt Mixture's Thermal Properties and Low Temperature Performance," ASCE Congress on Technical Adv.,2017

[30] A. Gudmarsson, N. Ryden, H. Di Benedetto, C. Sauzéat, N. Tapsoba, and B. Birgisson, "Comparing Linear Viscoelastic Properties of Asphalt Concrete Measured by Laboratory Seismic and Tension-Compression Tests," J. Nondestruct. Eval., vol. 33, no. 4, pp. 571-582, 2014

[31] A. Gudmarsson, N. Ryden, and B. Birgisson, "Non-contact excitation of fundamental resonance frequencies of an asphalt concrete specimen," AIP Conf. Proc., vol. 1650, no. 2015, pp. 14011408, 2015 